\title{
Renaissance et ascensions de l'âme. De la lanterne à la lune, de la lune au soleil, dir. E. CHAYES
}

\section{Maurizio Busca}

\section{OpenEdition}

\section{Journals}

\section{Edizione digitale}

URL: https://journals.openedition.org/studifrancesi/43654

DOI: 10.4000/studifrancesi.43654

ISSN: 2421-5856

\section{Editore}

Rosenberg \& Sellier

\section{Edizione cartacea}

Data di pubblicazione: 1 juin 2021

Paginazione: 202-203

ISSN: 0039-2944

\section{Notizia bibliografica digitale}

Maurizio Busca, «Renaissance et ascensions de l'âme. De la lanterne à la lune, de la lune au soleil, dir. E. CHAYES», Studi Francesi [Online], 193 (LXV | I) | 2021, online dal 01 juillet 2021, consultato il 15 octobre 2022. URL: http://journals.openedition.org/studifrancesi/43654 ; DOI: https://doi.org/10.4000/ studifrancesi.43654

Questo documento è stato generato automaticamente il 15 octobre 2022.

\section{(†) $\odot$

Creative Commons - Attribuzione - Non commerciale - Non opere derivate 4.0 Internazionale - CC BYNC-ND 4.0

https://creativecommons.org/licenses/by-nc-nd/4.0/ 


\title{
Renaissance et ascensions de l'âme. De la lanterne à la lune, de la lune au soleil, dir. E. CHAYES
}

\author{
Maurizio Busca
}

\section{NOTIZIA}

Renaissance et ascensions de l'âme. De la lanterne à la lune, de la lune au soleil, dir. E. CHAYES, Paris, Classiques Garnier, 2019, «Rencontres» 327, 206 pp.

1 I saggi raccolti nel presente volume prendono in esame un corpus tanto vasto quanto eterogeneo di rappresentazioni dell'ascesa dell'anima: vi troviamo opere di filosofi, teologi, mistici e artisti pagani, cristiani ed ebrei che, da Platone al primo Seicento, hanno tentato di illustrare quel che accade all'anima al momento della sua separazione dal corpo in occasione della morte o di esperienze estatiche. Ognuno degli otto contributi è dedicato ad una tradizione filosofica, teologica, mistica o iconografica differente, nell'intento dichiarato di fornire un repertorio rappresentativo delle principali teorie dell'ascesa dell'anima elaborate in Europa e nel Mediterraneo orientale dall'Antichità al Rinascimento. BELLI, CONSTANTINIDOU e PONCET in particolare, guardano al neoplatonismo quattro-cinquecentesco, alle sue diverse declinazioni e ai dibattiti fra neoplatonici e difensori di dottrine e scuole concorrenti (aristotelica, stoica, epicurea, cinica), mentre RAKOVSKY propone uno studio dedicato alla distinzione simbolica dei due occhi (il sinistro rivolto verso il mondo terrestre, il destro verso il mondo celeste) e alle sue implicazioni per le rappresentazioni letterarie e figurative dello sguardo. I contributi raccolti sono i seguenti.

2 Laurent LAVAUD, Initiation mystique et ascension philosophique. De Platon à Plotin, pp. 17-32; Ana Palanciuc, L'iconographie byzantine de la Dormition de la Vierge. Une controverse balkanique sur l'ascension de l'âme, pp. 33-58; Sophie DELMAS, L'ascension de l'âme après la mort chez quelques maîtres en théologie du XIII ${ }^{\mathrm{e}}$ siècle, pp. 59-73; 
Margherita BELLI, Neoplatonismo per adolescenti in alcuni commenti alla "Philosophiæ consolatio" di Severino Bœzio (1456-1656), pp.75-100; Natasha ConstANTINIDOU, Popularising the Classics. The Soul and its Ascent in Pierre Charron's "De la Sagesse, Trois Livres" (1601-1607), pp. 101-127; christophe PONCET, En montant l'échelle des philosophes. Marsile Ficin et la vision des Idées, pp.129-148; Daniel RAKOvsKY, Une ascension sans élévation. La distinction symbolique entre l'œil gauche et l'œil droit dans le portrait de la Renaissance, pp. 149-164; Moshe IDEL, Ascensions de l'Âme dans la "Kabbale" de Safed, pp. 165-183. 